\title{
Kanser hastalarında yaşam kalitesinin iyileştirilmesi ve uyku bozukluklarının tedavisinde uyku hijyeni ve psikopatolojinin yeri: Bir yol analizi çalışması
}

\section{The role of sleep hygiene and psychopathology in improving the quality of life and treatment of sleep disorders in cancer patients: A path analysis study}

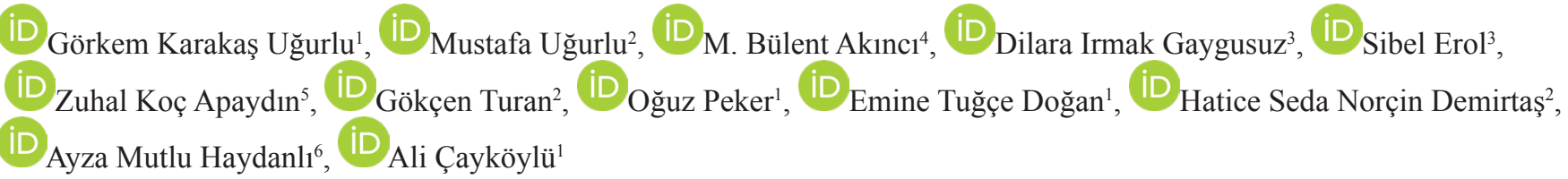

'Sağlık Bakanlı̆̆ı Ankara Şehir Hastanesi Psikiyatri Kliniği.

${ }^{2}$ AYBÜ Tıp Fakültesi Psikiyatri AD.

${ }^{3}$ TOBB Ekonomi ve Teknoloji Üniversitesi Psikoloji Bölümü.

${ }^{4}$ AYBÜ Tıp Fakültesi Tibbi Onkoloji AD.

${ }^{5}$ Karabük Eğitim ve Araştırma Hastanesi Psikiyatri Kliniği.

${ }^{6}$ İzmir Tepecik Eğitim ve Araştırma Hastanesi.

Öz

Amaç: Kanser hastalarında uyku bozuklukları, uyku hijyeni, psikopatoloji ve yaşam kalitesi kavramlarını bütüncül bir çerçevede ele alan az sayıda çalışma vardır. Özellikle uyku hijyeni erişkin kanser hastalarında uyku bozukluklarının tedavisinde yer almasına rağmen etkinliğine dair çalışma yoktur. Çalışmanın amacı bu kavramlar arasındaki ilişkilerin yön ve büyüklüklerini modellemek ve böylece klinik pratiğe katkı sunmaktır.

Yöntem: Bu çalıșma kanser tanısı almıș 34 katılımcı ve 16 sağlıklı kontrolden oluşan iki grup üzerinde yapılmıştır. Katılımcılar uyku hijyeni (Uyku Hijyeni Ölçeği -UHI-) ve uyku bozuklukları (Pitsburgh Uyku Kalitesi İndeksi -PUKİ- ve Eppworth Uykululuk Ölçeği -EUO-), psikopatoloji (Belirti Kontrol Listesi -SCL 90-) ve yaşam kalitesi (Kısa Form -SF 36-) bakımından karşılaştııılmıştır. Ayrıca bu değişkenler arasındaki ilişkiler, nedensellik bağlamında, bir model ile test edilmiştir.

Bulgular: Kanser hastalarında uyku hijyeni, uyku sağlığ 1 , ruh sağlı̆̆ ve yaşam kalitesi kontrol grubuna göre anlamlı düzeyde bozulmuştur (Sırasılya; $p U H \dot{I}=0,031$, pPUKİ=0,046, pSCL-90=0,008 ve pSF-36<0,001). Ancak uyku hijyeninde bozulmanın uyku bozuklukları, psikopatoloji ve yaşam kalitesi üzerinde etkisi saptanmamıştır. Uyku bozukluklarının psikopatolojideki artışa ikincil olarak geliştiği saptanmıştır.

Sonuç: Kanser hastalarında uyku bozukluklarının tedavisinde uyku hijyeni önerileri hastaya göre ve dikkatli seçilmeli ve etkileri sınırlı olabileceği için bu hastalarda uyku bozukluklarındaki gidişin yakından izlenmesi gereklidir. Ayrıca kanser hastalarında uyku bozuklukları ve yaşam kalitesinin iyileştirilmesinde temel hedefin hastadaki psikopatoloji düzeyi olması gerektiği sonucuna ulaşılmıştır.

Anahtar kelimeler: kanser, psikopatoloji, uyku, uyku hijyeni, yaşam kalitesi

Abstract

Objective: There are few studies that address the concepts of sleep disorders, sleep hygiene, psychopathology and quality of life in a holistic framework in cancer patients. Although sleep hygiene is particularly involved in the treatment of sleep disorders in adult cancer patients, there is no study on its effectiveness. The aim of the study is to model the directions and sizes of the relationships between these concepts and thus contribute to clinical practice.

Method: This study was conducted on two groups consisting of 34 participants diagnosed with cancer and 16 healthy controls. Participants were compared in terms of sleep hygiene (Sleep Hygiene Index -SHI-) and sleep disorders (Pittsburgh Sleep Quality Index -PSQI- and Epworth Sleepiness Scale -ESS-), psychopathology (Symptom Checklist 90 -SCL 90-), and quality of life (Sort Form 36-SF 36-). In addition, the relationships between these variables were tested with a model in the context of causality.

Results: Sleep hygiene, sleep health, mental health and quality of life were significantly impaired in cancer patients compared to the control group (Respectively; pSHI=0,031, pPSQI $=0,046$, pSCL-90=0,008 ve pSF-36<0,001). However, impairment in sleep hygiene has not been found to have an effect on sleep disorders, psychopathology and quality of life. Sleep disorders have been found to develop secondary to the increase in psychopathology.

Conclusion: In the treatment of sleep disorders in cancer patients, sleep hygiene recommendations should be chosen according to the patient and carefully, and since their effects may be limited, the course of sleep disorders in these patients should be closely monitored. In addition, it was concluded that the main goal in improving sleep disorders and quality of life in cancer patients should be the level of psychopathology in the patient.

Keywords: cancer, sleep, sleep hygiene, psychopathology, quality of life

Bu çalışmanın ön bulguları 14-16 Kasım 2018 tarihinde Ankara'da yapılan I. Psikoonkoloji Kongresinde poster bildirimleri olarak sunulmuştur.

Yazışma Adresi: Mustafa Uğurlu, Sağlık Bakanlığı Ankara Şehir Hastanesi, Psikiyatri Kliniği, Ankara, Türkiye.

E-Posta: dr ugurlu@yahoo.com

Alınma tarihi: 19.10.2020 / Kabul tarihi: 09.08.2021 / Yayımlanma tarihi: 15.12.2021

Kanser hastalarında uyku, psikopatoloji ve yaşam kalitesi arasındaki

Genel Tip Derg 2021;31(4)344-348

ilişkilerin modellenmesi - Karakuş Uğurlu ve ark. 


\section{Giriş}

Kanser hastalarında uyku problemleri, özellikle de insomnia, genel popülasyonun yaklaşık iki katı sıklıkta gözlenmektedir(1). Kanserin türüne, lokalizasyonuna, tedavisine ve evresine göre uyku bozukluklarının niteliği ve şiddeti değişmektedir(2). Kanser hastalarında insomnianın ilk sıra tedavisi bilişsel davranışçı tedavidir (BDT). BDT uykuyla ilgili uyumsal olmayan düşünce ve inançların bilişsel yeniden yapılandırma yöntemleri ile ele alınmasını, gevşeme-nefes egzersizlerini ve uyku hijyeni olarak tanımlanan bir sıra davranışçı önerileri kapsar. Uyku hijyeni sağlıklı bir uykuyu başlatmak ve sürdürmek için gerekli davranışları ve çevresel faktörleri tanımlar. Bunlar arasında yatma ve uyanma saatlerinin stabilitesinin sağlanması, aşırı kafein tüketiminin azaltılması, uyanık olarak yatakta geçirilen sürenin kısıtlanması, düzenli egzersiz yapılması, yatak odasında TV izlemek, cep telefonu ile vakit geçirmek, çalışmak gibi aktivitelerin sınırlanması sayılabilir(3).

Kanser hastalarında uyku bozukluklarıyla beraber psikiyatrik hastalıklar da sık gözlenir. Bunların başında depresyon ve anksiyete bozuklukları gelmektedir. Kanser ve tedavilerinin doğrudan ve dolaylı etkileri (fiziksel deformiteler, kanser tanı ve tedavisinin getirdiğ belirsizlikler ve yeni roller gibi) hastayı psikiyatrik hastalıklara yatkın bir konuma getirir(4). Psikiyatrik hastalıkların ve genel sağlığın yaşam kalitesi üzerindeki önemi düşünüldüğünde pek çok kanser hastasında yaşam kalitesi bozulur(5).

Uyku hijyeni bugüne kadar kanser hastalarında gözlenen uyku bozukluklarında tedavinin bir parçası olarak çalışılmış ancak erişkin kanser hastalarında uyku hijyeninin nasıl etkilendiği doğrudan araştırılmamıştır. Bu çalışmanın amacı, bir bütün olarak ele alınması gerektiğini düşündüğümüz uyku, uyku hijyeni, psikopatoloji, genel sağlık ve yaşam kalitesi arasındaki ilişkileri bir model üzerinden ortaya koymak ve bu model üzerinden kanser hastalarında yaşam kalitesini arttıracak tedavi stratejileri geliştirmektir.

\section{Yöntem}

Çalışma için etik kurul onayı alınmış ve çalışma öncesinde her bir katılımcı için bilgilendirilmiş onam alınmıştır. Hasta grubu bir eğitim araştırma hastanesi onkoloji polikliniğine başvuran hastalardan ardışık olarak seçilmiştir. Çalışmaya 18-65 yaş arasında olan kanser hastaları ve demografik açıdan eşleştirilmiş sağlıklı kontroller dahil edilmiştir. Hasta grubunda, son 6 ayda psikiyatrik tanı almış olan ya da psikiyatri ilacı kullanan, 18 yaşından küȩük, 65 yaşından büyük olan, uyku bozuklukları için ilaç tedavisi kullanan, genel durumu bozuk olan ve merkezi sinir sistemi (MSS) tutulumu olan hastalar; kontrol grubunda ise, son 6 ayda psikiyatrik tanı almış olan ya da psikiyatri ilacı kullananlar, 18 yaşından küçük, 65 yaşından büyük olanlar, uyku bozuklukları için ilaç tedavisi kullananlar çalışma dışında bırakılmışlardır.

Hasta ve sağl1klı kontrollerle demografik bilgileri toplamak ve onam almak için yüz yüze görüşmeler yapılmıştır. Her bir katılımcıya öz bildirim formları hakkında kısa bir açıklama yapıldıktan sonra doldurmaları için 30 dakikalık süre ve uygun bir ortam verilmiştir. Çalışmada kullanılan ölçek formları şöyledir;

Pittsburgh Uyku Kalitesi Ölçeği (PUKİ): Son bir aylık bir zamanda uyku kalitesi ve bozukluklarını belirlemek için kullanılan bir ölçektir. Uyku kalitesi, uyku latansı, uyku süresi, uyku etkinliği, uyku bozuklukları, uyku ilacı kullanımı ve uyku bozukluklarına bağlı günlük işlevsellikteki bozulmaları değerlendirir. Ölçek puanlarında artı̧̧ uyku kalitesinde bozulmaya işaret eder(6). Türkçe uyarlama çalışması Ağargün ve ark. tarafından yapılmıştır(7).

Epworth Uykululuk Ölçeği (EUÖ): Sekiz maddeden oluşan dörtlü likert tipi bir ölçektir. Gün içinde aşırı uykulu olma halini ölçer ve yüksek puanlar gündüz uykululuğuna işaret eder(8). Türkçe formunun uyarlaması İzci ve ark. tarafından yapılmıştır(9).

Uyku Hijyeni İndeksi(UHI): Onüç sorudan oluşan likert tipi bir ölçektir. Maladaptif uyku alışkanlıklarını değerlendirir ve yüksek puanlar kötü uyku hijyenine işaret eder(10). Türkçe uyarlaması Özdemir ve ark. tarafından yapılmıştır(11).

Yaşam Kalitesi Ölçeği Kısa Formu (SF-36): Yaşam kalitesini çeşitli alt boyutlarda ölçen likert tipi öz bildirim ölçeğidir. Kanser hastalarında Türkçe uyarlaması Pınar ve ark. tarafından yapılmıştır(12). Yüksek puanlar yaşam kaltesinin iyi olduğuna işaret eder(13).

Belirti Tarama Listesi (Symptom Checklist-SCL-90): 90 maddeden oluşan likert tipi bir ölçektir. Çeşitli psikopatoloji düzeylerini belirlemek için 9 alt boyut ve toplam puanlar verir. Kesme noktas1 her bir alt boyut ve genel psikopatoloji için 1 ve üzeridir(14). Türkçe uyarlaması Dağ ve ark. tarafından yapılmıştır(15).

Çalışmada tanımlayıcı istatistikler ortalama \pm standart sapma ve ortanca ya da frekans ve oran (\%) olarak verilmiştir. İkili karşılaştırmalarda student-t testi ve Mann Withney U testi kullanılmıştır. Kurulan modelde uyum iyiliği testleri için Uyum İndeksinin İyiliği (Goodness of Fit Index, GFI), Karşılaştırmalı Uyum İyiliği (Comparative Fit Index, CFI), Minimum tutarsızlık / serbestlik derecesi (CMIN/Df) ve Hata Kareler Ortalamasının Tahmini Kökü (Root Mean Square Error of Approximation, RMSEA) değerleri kullanılmıştır. Buna göre $\mathrm{CMIN} / \mathrm{Df} \leq 3$, RMSEA $\leq 0,05,0,90 \leq$ GFI ve $0,97 \leq \mathrm{CFI}$ iyi uyum olarak kabul edilmektedir(16).

\section{Bulgular}

Çalışmaya 50 hasta ve 30 sağlıklı kontrol davet edilmiştir. Hasta grubunda 16 , kontrol grubunda ise 14 katılımcı bilgilendirilmiş onamı imzalamak istemedikleri için ya da ölçek formlarını \% 10'dan fazla eksik doldurdukları için çalışma dışında bırakılmışlardır. Sonuç olarak 34 hasta ve 16 sağlıklı kontrole ait veriler analize dâhil edilmiştir.

Kontrol grubunda katılimciların 11'i $(\% 68,8)$, hasta grubunda ise 25 'i $(\% 69,4)$ kadındı ve cinsiyet bakımından gruplar arasında fark saptanmad $1\left(\chi^{2}(1)=0,123\right.$ ve $\left.p=0,726\right)$. Kontrol grubunda yaş ortalamas1 $37,6 \pm 9,4$, hasta grubunda ise $52,9 \pm 16,2$ idi ve gruplar arasında anlamlı fark saptand $1(\mathrm{t}(48)=-3,477$ ve $\mathrm{p}=0,001)$. Hasta grubu $16(\% 47,1)$ meme kanseri, 4 akciğer kanseri $(\% 11,8)$ ve $14(\% 41,1)$ diğer organ ve sistem kanseri tanısı almış vakalardan oluşmaktaydı. Hastaların \%12,5'i kemoterapi (KT), \%18,8'i cerrahi tedavi (CT), \%9,4'ü radyoterapi (RT)+KT, \%31,3’ü KT+CT ve $\% 26,5$ 'i RT $+\mathrm{KT}+\mathrm{CT}$ almaktayd. Hasta grubunda hastalık süresi ortalama 2,6 $\pm 3,2$ yıldi.

Gruplar arasında uyku özellikleri, psikiyatrik semptomatoloji ve yaşam kalitesi puanlarının karşılaştırılması tablo 1 ve 2'de verilmiştir.

Şekil 1 de ise hastalığın uyku kalitesi, uyku hijyeni, psikiyatrik

Kanser hastalarında uyku, psikopatoloji ve yaşam kalitesi arasındaki ilișkilerin modellenmesi - Karakuș Uğurlu ve ark. 
Tablo 1: Gruplar arasında uyku parametrelerinin karşıllaştırılması

\begin{tabular}{|c|c|c|c|c|c|c|c|c|c|c|c|}
\hline & \multicolumn{5}{|c|}{$\mathrm{K}$} & \multicolumn{5}{|c|}{$\mathrm{H}$} & \multirow{3}{*}{$\mathrm{p}$} \\
\hline & \multirow[t]{2}{*}{ Ort. } & \multirow[t]{2}{*}{ S.S } & \multicolumn{3}{|c|}{ Çeyreklikler Arası Yüzde } & \multirow[t]{2}{*}{ Ort. } & \multirow[t]{2}{*}{ S.S } & \multicolumn{3}{|c|}{ Çeyreklikler Arası Yüzde } & \\
\hline & & & 25 & 50 & 75 & & & 25 & 50 & 75 & \\
\hline UHI-T & 12,1 & 7,6 & 7,0 & 9,5 & 16,0 & 18,2 & 9,7 & 12,0 & 17,0 & 23,3 &, $031 *$ \\
\hline EUO-T & 5,0 & 3,3 & 2,0 & 4,0 & 7,8 & 5,4 & 5,2 & 1,0 & 5,0 & 8,3 &, $790^{*}$ \\
\hline PUKI-T & 5,8 & 3,5 & 4,0 & 5,0 & 6,8 & 8,2 & 3,9 & 5,0 & 7,5 & 12,0 &, $046^{*}$ \\
\hline PUKI-UK & 1,3 &, 7 & 1,0 & 1,0 & 1,8 & 1,6 & 1,2 & 1,0 & 1,0 & 3,0 &, 367 \\
\hline PUKI-UL & 9 & 8 & 0 & 1,0 & 1,8 & 1,4 & 1,0 & 0 & 1,5 & 2,0 & ,103 \\
\hline PUKI-US & 8 & 8 & 0 & 1,0 & 1,0 & 1,2 & 1,1 & 0 & 1,0 & 2,0 &, 305 \\
\hline PUKI-UE &, 3 & 8 & 0 & 0 & 0 &, 7 & 1,2 & 0 &, 0 & 1,3 & 263 \\
\hline PUKI-UB & 1,4 & 6 & 1,0 & 1,5 & 2,0 & 2,0 &, 7 & 2,0 & 2,0 & 2,0 & 013 \\
\hline PUKI-Uİ & , 2 &, 5 & 0 & 0 & 0 & ,2 &, 7 & 0 &, 0 & 0 &, 971 \\
\hline PUKI-GF & 9 & 9 & 0 & 1,0 & 1,8 & 1,1 & 1,1 & 0 & 1,0 & 2,0 &, 861 \\
\hline
\end{tabular}

*Student $\mathrm{t}$ test, diğer karşılaştırmalar Mann Withney U test

K: Kontrol grubu, H: Hasta grubu, UHI-T: Uyku Hijyeni İndeksi toplam puanı, EUO-T: Eppworth Uykululuk İndeksi toplam puan1, PUKİ-T: Pitsburgh Uyku Kalitesi İndeksi toplam puanı, PUKİ alt boyutları: UK; Uyku Kalitesi, UL; Uyku Latansı, US; Uyku Süresi, UE; Uyku

Etkinliği, UB; Uyku Bozukluğu, Uİ; Uyku İlacı kullanımı, GF; Gündüz fonksiyonelliği

Tablo 2: Gruplar arasında yaşam kalitesi ve psikopatoloji parametrelerinin karşılaştırılması

\begin{tabular}{|c|c|c|c|c|c|c|c|c|c|c|c|}
\hline & \multicolumn{5}{|c|}{ K } & \multicolumn{5}{|c|}{$\mathrm{H}$} & \multirow[t]{3}{*}{$\mathrm{p}$} \\
\hline & \multirow[t]{2}{*}{ Ort. } & \multirow[t]{2}{*}{ S.S } & \multicolumn{3}{|c|}{ Çeyreklikler Arası Yüzde } & \multirow[t]{2}{*}{ Ort. } & \multirow[t]{2}{*}{ S.S } & \multicolumn{3}{|c|}{ Çeyreklikler Arası Yüzde } & \\
\hline & & & 25 & 50 & 75 & & & 25 & 50 & 75 & \\
\hline SF-36-T & 69,1 & 11,6 & 61,9 & 66,1 & 80,5 & 49,9 & 22,4 & 32,2 & 52,4 & 69,2 & $<, 001$ \\
\hline SF-FF & 87,2 & 14,7 & 81,3 & 95,0 & 98,8 & 59,7 & 22,4 & 48,8 & 65,0 & 76,3 & $<, 001$ \\
\hline SF-RGf & 73,5 & 33,5 & 56,3 & 75,4 & 100,0 & 25,0 & 33,1 &, 0 & 12,9 & 50,0 & $<, 001 *$ \\
\hline SF-RGe & 62,5 & 43,7 & 8,3 & 83,3 & 100,0 & 40,2 & 44,8 &, 0 & 33,3 & 100,0 &, $115^{*}$ \\
\hline SF-V & 50,6 & 22,7 & 36,3 & 50,0 & 73,8 & 46,0 & 26,9 & 28,8 & 42,5 & 66,3 & ,558 \\
\hline SF-RS & 63,3 & 22,1 & 46,0 & 70,0 & 79,0 & 57,9 & 24,9 & 36,0 & 58,0 & 80,0 & ,466 \\
\hline SF-Sİ & 71,9 & 19,6 & 50,0 & 75,0 & 84,4 & 63,2 & 37,6 & 34,4 & 68,8 & 100,0 &, $782 *$ \\
\hline SF-P & 68,9 & 19,5 & 57,5 & 72,5 & 79,4 & 50,8 & 36,1 & 18,1 & 50,0 & 80,0 &, 026 \\
\hline SF-GSA & 63,4 & 16,4 & 50,0 & 60,0 & 75,0 & 56,2 & 27,3 & 35,0 & 55,0 & 80,0 &, 250 \\
\hline SCL-90-T &, 1 &, 0 &, 0 &, 0 &, 1 &, 1 &, 1 &, 0 &, 1 &, 2 &, 008 \\
\hline SCL-OKB & 1,0 & 6 &, 5 & 1,0 & 1,2 & 1,4 & ,9 & 6 & 1,3 & 2,2 & ,028 \\
\hline SCL-DEP &, 9 &, 8 &, 3 & 6 & 1,2 & 1,4 & 1,0 & 6 & 1,2 & 2,1 & ,093 \\
\hline SCL-ANX & 6 & 6 &, 2 &, 4 & 1,1 & 1,1 & ,9 &, 2 & 1,2 & 1,5 &, 052 \\
\hline SCL-O/D & 6 &, 7 &, 2 &, 5 & 1,0 & 1,0 & ,9 &, 3 &, 7 & 1,7 &, $117^{*}$ \\
\hline SCL-F &, 3 &, 5 &, 0 &, 1 &, 3 & 8 & ,9 &, 0 &, 5 & 1,5 &, $097 *$ \\
\hline SCL-PAR &, 7 &, 7 &, 2 &, 5 & 1,3 & 1,3 & 1,1 &, 3 & 1,3 & 2,0 &, $112 *$ \\
\hline SCL-PSI &, 4 &, 4 &, 1 &, 3 &, 8 &, 7 & 6 &, 3 &, 8 & 1,0 &, 056 \\
\hline SCL-EK-S &, 7 & 6 &, 2 &, 4 & 1,4 & 1,6 & 1,0 & 6 & 1,7 & 2,5 & $<, 001$ \\
\hline
\end{tabular}

*Mann Withney U test, diğer karşılaştırmalar student t test

K: Kontrol grubu, H: Hasta grubu, SF-36-T: Yaşam Kalitesi Ölçeği Kısa Formu toplam puan1, SF-36 alt boyutları: FF; Fiziksel Fonksiyonnellik, RGf; Fiziksel Rol Güçlüğü, RGe; Emosyonel Rol Güçlüğü, V; Vitalite, RS; Ruhsal Sağlık, Sİ; Sosyal İşlevsellik, P; Ağrı, GSA; Genel Sağlık Alg1sı. SCL-90; Symptom Check List, SCL-90 alt boyutları: SOM; Somatizayon, OKB; Obsessif Kompulsif Bozukluk, DEP; Depresyon, ANX; Anksiyete, Ö/D; Öfke-Düşmanlık, F; Fobik anksiyete, PAR; Paranoya, PSI; Psikopati, EK-S; Ek Skalalar. 
semptomatoloji ve yaşam kalitesi üzerindeki etkileri modellenmiştir. Modele göre kanser hastalığının uyku hijyenini doğrudan olumsuz etkilediği saptanmıştır. Uyku hijyenin diğer parametreler üzerinde anlamlı bir etkisinin olmadığı gözlenmiş̧ir. Kanser hastalığının uyku kalitesi üzerinde doğrudan bir etkisinin olmadığı, ancak psikopatoloji düzeylerini arttırmak yoluyla uyku kalitesini olumsuz etkilediği, bununla beraber, artan psikopatoloji düzeylerinin gündüz uykululuk halini arttırdığı saptanmıştır. Son olarak genel psikopatoloji ve uyku kalitesindeki bozulmanın kanser hastalarında yaşam kalitesini anlamlı derecede olumsuz etkilediği bulunmuştur. Yaş değişkeni modele etkilendiğinde hiçbir parametre üzerinde anlamlı etkiye sahip olmadığı görülmüş ve modelden çıkarılmıştır.

Şekil 1: Kanser hastaları ve sağlıklı kontrollerde uyku hijyeni, uyku kalitesi ve psikopatoloji düzeylerinin yaşam kalitesi üzerindeki etkisinin modellenmesi

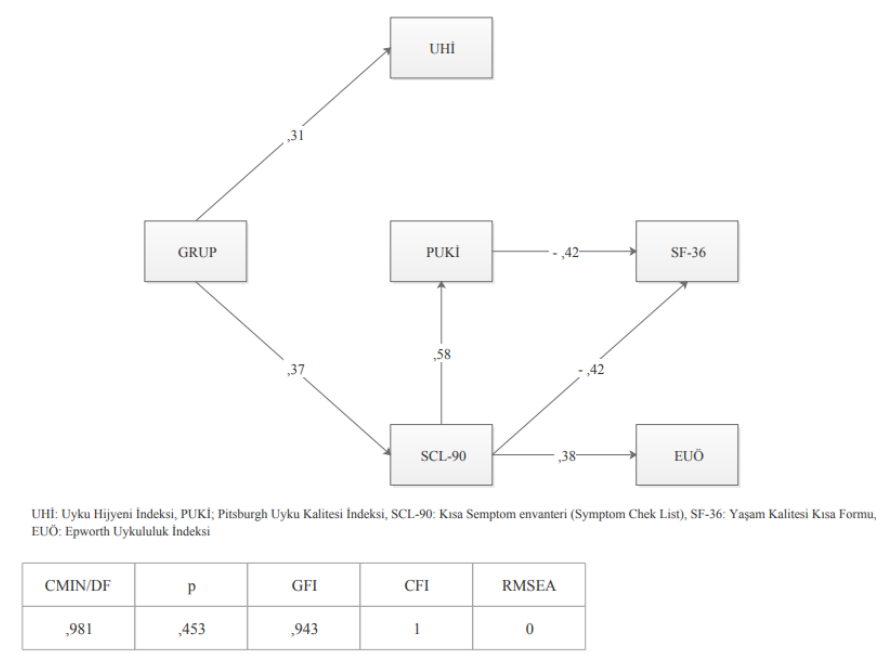

\section{Tartışma}

$\mathrm{Bu}$ çalışma erişkin kanser hastalarında uyku hijyeni ile uyku bozukluklarını psikopatoloji ve yaşam kalitesi bağlamında ele almaya çalışmıştır. Literatürde erişkin kanser hastalarında uyku bozukluklarının tedavisinde kullanılan bir yöntem olan BDT'nin bir parçası ve uyku problemlerinin tedavisindeki hedeflerden biri olarak uyku hijyeni ele alınmıştır(17, 18) ancak erişkin kanser hastalarında uyku hijyeninin doğrudan nasıl etkilendiğini araştıran bir çalışmaya rastlanmamıştır. Adolesan kanser hastalarında kemoterapi sırasında uyku hijyenini değerlendiren bir çalışma vardır(19). Bu çalışmada uyku hijyeninin stabilite (yatış ve kalkış zamanında değişimler), çevre (uygun ortam) ve biliş (uyku öncesi uykuya dair düşünceler) alt boyutlarında anlamlı bozulma bulunmuştur. Bizim çalışmamızda da kanser hastalarında uyku hijyeni, sağlıklı katılımcılara göre anlamlı biçimde bozuk bulunmuştur. Ancak UHİ'nin alt boyutları olmadığı için her bir madde ayrı ayrı incelenmiş ve birinci madde ("gündüz saatlerinde 2 saat ya da daha fazla şekerleme yaparım") ve 12. maddeden ("yatmadan önce önemli işler yaparım (faturaları ödeme, plan yapma veya çalışma gibi)") alınan puanların sağlıklı kontrollerden daha yüksek olduğu saptanmıştır. Kanser hastalarında hastalığa ve tedavilere bağlı olarak yorgunluk sık görülür. Hastaların birçoğunda yorgunlukla uygunsuz biçimde baş edilir ve gündüzleri dinlenme ya da uyuma gibi davranışlara yönelme sıktır. Yine kanser hastalarının tanı ve tedavi boyunca sağlıkları için yapmaları gereken çok sayıda iş vardır. Hasta doktor randevularını, tetkikleri, tedavi uygulamalarını, günlük yaşamdaki değişimleri ve bunlara ayak uydurmak için yapılması gerekenleri, mali konuları, ailesel problemler gibi planlanması ve uygulanması oldukça fazla zaman alacak birçok konuyu ancak uyku zamanında ele almak zorunda kalabilir.

$\mathrm{Bu}$ çalışmanın ortaya koyduğu ilginç sonuçlardan biri kanser hastalarında uyku hijyeni bozulmuş olsa da bunun uyku sağlığı üzerinde anlamlı bir etkisinin olmamasıdır. Şekil 1 incelendiğinde görüldüğü üzere kanser doğrudan kansere bağl1 sebeplerle uyku hijyeni bozuyor ya da değiştiriyor gibi görünmektedir. Ancak uyku hijyenindeki değişimin ne uyku bozukluklarına ne de yaşam kalitesine doğrudan bir etkisi söz konusu değildir.

Çalışmanın bulduğu ikinci önemli sonuç ise kanser hastalarında uyku bozukluklarının (PUKİ-T ve EUÖ-T puanları üzerinden) tanı ya da tedaviden doğrudan etkilenmediği ancak kansere bağlı artan ya da ortaya çıkan psikopatolojilere ikincil olarak ortaya çıktıkları ya da arttıklarıdır. Yani kanser psikopatoloji düzeylerini arttırmakta bu da uyku problemlerine yol açmaktadır. Nitekim kanser hastalarında uyku bozukluklarının tedavisinde kullanılan BDT tekniklerinin uyku üzerinde olumlu etkileri belki de direkt olarak değil bu tekniklerin anksiyete ve depresyon üzerinde de olumlu etkilerinden kaynaklanıyor olabilir. Özellikle de uyku ile ilgili uyumsal olmayan inanç ve düşüncelerin değiştirilmesinde kullanılan bilişsel yeniden yapılandırma teknikleri anksiyete ve depresyon belirtileri için de kullanılabilir.

Son olarak çalışma ortaya koymaktadır ki kanserin yaşam kalitesi üzerinde olumsuz etkileri doğrudan değil psikopatoloji üzerindeki olumsuz etkiler sonucundadır. Ancak uyku bozuklukları (PUKİ-T puanları) da dolaylı olarak yaşam kalitesini olumsuz etkilemektedir. Kanser hasta için pek çok bedensel ruhsal ve sosyal yükü beraberinde getirir ve yaşam kalitesini bozar. Yaşam kalitesinde iç ve dış uyaranların önemi büyüktür ancak bireyin kendi ruhsal, fiziksel ve sosyal sağlı̆̆ını nasıl algıladığı sonucu belirleyen en önemli etkendir. Dolayısıyla bu algıyı olumsuz etkileyecek ve gerçekliği bütünüyle değerlendirme şansını azaltacak depresyon ya da anksiyete gibi bozukluklar yaşam kalitesinin daha da olumsuz algılanmasına neden olacaktır. Kanser hastalarında yaşam kalitesini arttırmanın yolu kanserin tıbbi tedavisi ve iyi bir tıbbi bakımdan geçmekle beraber bu hastaların ruhsal ihtiyaçlarının karşılanması ve ruhsal problemlerinin giderilmesi de son derece önemlidir.

Çalı̧̧manın sınırlılıklarından birisi örneklem büyüklüğüdür. Her ne kadar örneklem büyüklüğü küçük görünse de modelleme analizlerinde hem iyi model uyumu sağlanmış hem de örneklem büyüklüğünün analizler için yeterli olduğu gösterilmiştir (model c.r=1,59<10)(20). İkinci bir sınırlılık hasta ve kontrol grubu arasında yaşın anlamlı farka sahip olmasıdır. Bu sınırlılık yaş değişkenin etkisini kontrol edebilmek için eş değişken olarak modele alınması ile aşılmıştır. Yaş ile beraber model yeniden analiz edildiğinde yaşın herhangi bir değişken üzerinde anlamlı etkisi olmadığı ve model uyum iyiliği sonuçlarında anlamlı bir değişiklik oluşturmadığ 1 gözlenmiş ve yaş değişkeni modelden çıkarılmıştır.

$\mathrm{Bu}$ çalışma erişkin kanser hastalarında uyku hijyeninin nasıl etkilendiğini araştıran ilk çalışmadır. Ayrıca uyku hijyeni ve uyku bozukluklarını kansere bağlı psikopatoloji ve yaşam kalitesi bağlamında ele alan bir metodolojik modele sahiptir. Böylece bu 
kavramlar karşılıklı etkileşimleri ile bir bütün olarak incelenebilir. $\mathrm{Bu}$ model aynı zamanda klinik pratiğe de gönderme yapmaktadır. Kanser hastalarında uyku problemleri uyku hijyeninde bozulma ile ilişkili bulunmadığından bu hastalarda uyku hijyenine dair davranışçı önerilerin dikkatle ve hastaya göre seçilmesi ve etkinliği sınırlı olabileceği için iyi takip edilmesi gerekmektedir. Ayrıca çalışmamız kanser hastalarında uyku problemlerinin psikopatolojiye ikincil geliştiğine işaret etmektedir ve bu da kanser hastalarında uyku bozukluklarını tedavi ederken mutlaka altta yatan psikiyatrik hastalıkların taranması ve varsa tedavi edilmesi gerektiği sonucuna varmamıza neden olur. Aksi halde uyku bozukluklarının tedavisinde kullanılan diğer yöntemlerin etkisi sınırlı kalacak ve yaşam kalitesini yükseltme firsatı değerlendirilememiş olacaktır.

\section{Kaynaklar}

1.Voiss P, Höxtermann MD, Dobos G, et al. Cancer, sleep problems, and mindbody medicine use: Results of the 2017 National Health Interview Survey. Cancer 2019;125:4490-7

2.Scharf M, Kasinathan N, Sunderram J. Sleep disorders in critically ill cancer patients. In: Nates J., Price K. (eds) Oncologic Critical Care. Springer, Cham. 2020;699-707.

3.Ma Y, Hall DL, Ngo LH, et al. Efficacy of cognitive behavioral therapy for insomnia in breast cancer: A meta-analysis. Sleep Med Rev. 2020:101376.

4.İzci F, İlgün AS, Fındıklı E, et al. Psychiatric symptoms and psychosocial problems in patients with breast cancer. J Breast Health. 2016;12:94.

5.Toussi A, Barton VR, Le ST, et al. Psychosocial and psychiatric comorbidities and health-related quality of life in alopecia areata: A systematic review. J Am Acad Dermatol. 2020 .

6.Buysse DJ, Reynolds III CF, Monk TH, et al. The Pittsburgh Sleep Quality Index: A new instrument for psychiatric practice and research. Psychiatry Res. 1989;28:193-213.

7.Ağargün MY, Kara H, Anlar Ö. The validity and reliability of the Pittsburgh Sleep Quality Index. Turk Psikiyatri Derg. 1996;7:107-15.

8.Johns MW. Reliability and factor analysis of the Epworth Sleepiness Scale. Sleep. 1992;15:376-81.

9.Izci B, Ardic S, Firat H, et al. Reliability and validity studies of the Turkish version of the Epworth Sleepiness Scale. Sleep Breath. 2008;12:161-8.

10. Mastin DF, Bryson J, Corwyn R. Assessment of sleep hygiene using the Sleep Hygiene Index. J Behav Med. 2006;29:223-7.

11.Ozdemir PG, Boysan M, Selvi Y, et al. Psychometric properties of the Turkish version of the Sleep Hygiene Index in clinical and non-clinical samples. Compr Psychiat. 2015;59:135-40.

12.Pinar R. Reliability and construct validity of the SF-36 in Turkish cancer patients. Qual Life Res. 2005;14:259-64.

13.Ware J, John E, Gandek B. The SF-36 Health Survey: Development and use in mental health research and the IQOLA Project. Int J Ment Health. 1994;23:49-73.

14.Derogatis LR, Cleary PA. Confirmation of the dimensional structure of the SCL-90: A study in construct validation. J Clin Psychol. 1977;33:981-9.

15.Dağ İ. Belirti Tarama Listesi (Scl-90-R)'nin Üniversite Öğrencileri için güvenirliği ve geçerliği. Turk Psikiyatri Derg. 1991;2:5-12

16.Schermelleh-Engel K, Moosbrugger H, Müller H. Evaluating the fit of structural equation models: Tests of significance and descriptive goodness-of-fit measures. MPROnline. 2003;8:23-74.

17. Savard J, Simard S, Ivers H, et al. Randomized study on the efficacy of cognitivebehavioral therapy for insomnia secondary to breast cancer, part I: Sleep and psychological effects. J Clin Oncol. 2005;23:6083-96.

18.Berger AM, VonEssen S, Kuhn BR, et al. Adherence, sleep, and fatigue outcomes after adjuvant breast cancer chemotherapy: Results of a feasibility intervention study. Oncol Nurs Forum. 2003;30:513-522

19.Walker AJ, Johnson KP, Miaskowski C, et al. Sleep Quality and Sleep Hygiene Behaviors of Adolescents during Chemotherapy. J Clin Sleep Med. 2010;06:439-44.

20.Kline R. Principles and Practice of Structural Equation Modeling. Ed. Ke-3. New York: The Guilford Press; 2011 